\title{
Sense of Security and Production of Place in Gated Communities: Case- studies in Lagos, Nigeria
}

\author{
Ilesanmi Adetokunbo \\ Department of Architecture, Obafemi Awolowo University, Ile-Ife, Nigeria \\ aoikcom@yahoo.com
}

\begin{abstract}
The emergence of Gated Communities (GCs) represents one of the most intriguing phenomena and a crucial debate in an urbanizing globe. This study explored the link between sense of security and the negotiation of place by examining the potentials for place production in gated communities (GCs). Although a dearth of comprehensive data presently exists on GCs in Lagos, their increasing emergence is apparent. This research adopted a case-study approach, collecting primary data through field observations and qualitative in-depth interviews with eighteen (18) residents of four (4) purposively selected gated estates out of twenty (20) estates identified from preliminary mapping exercises. The qualitative data were subjected to content analysis and comparative evaluation. Findings reveal that characteristics that suggest the potential for place production vary according to the evolution and types of the gated developments. The medium-income gated estates originally built as public housing evidenced greater sense of security and place prospects than the private gated estates for the more affluent. The study concluded that the security-driven motive of gated communities could be a dominant factor in the negotiation of place, thus reinforcing the possible link between sense of security and production of place in gated communities.
\end{abstract}

Key words: Gated communities, negotiation of place, place production, security.

\section{INTRODUCTION}

The occurrence of Gated Communities (GCs) has been described as one of the most intriguing phenomena in cities all over the world, and a "radical urban form" which proliferates various socio-political contexts, and raises both heated emotions and significant questions on its emergence and consequences (Mostowska, 2007). This is reflected in the global phenomenon of a growing consumption of fortified lifestyle by many urban dwellers, and the proliferation of GCs in many metropolitan areas. GCs represent an evolving urban pattern in many cities of the world, and a significant issue of discussion in a rapidly urbanising globe. This paper explored the link between sense of security and the negotiation of place in gated communities. It examined how the perceived need for security could be a contributory force in the production of place - the potentials for place production in gated communities (GCs).

Although there is a lack of unanimity on the definition of GCs, most descriptions refer to housing developments that restrict public access, through the use of gates, barriers, walls and fences; or through the employment of security staff or CCTV systems to monitor access. Blakely and Snyder (1997) define gated communities as "residential areas with restricted access in 
which normally public spaces have been privatized. They are security developments with designated perimeters, usually walls or fences, controlled entrances that are intended to prevent penetration by non-residents." A key element of this type of housing development is therefore an effort to ensure one or more of these: security, privacy, and exclusivity.

Based on their legal and governance dimensions, Atkinson and Blandy (2005) define gated communities as: walled or fenced housing developments, which restrict public access and have legal agreements tying the residents to a common code of conduct and collective responsibility for management. According to Libertun de Duren (2007), gated living often means signing up to communally agreed arrangements that allow for money to be charged for maintenance of common-buildings and shared services, such as waste collection, street lighting, park management, and neighbourhood security staff.

From a perspective of their public-private spatial dialectic, Blakely (2007) views GCs as residential developments with restricted access to non-residents, such that spaces normally considered public have been privatized. Blandy (2007) also opines that the privatization of public space and the fortification of the urban realm, in response to the fear of crime and the need for security, significantly account for the growth in GCs. Many studies confirm increased global spread in the drive to redefine territory and protect neighbourhood boundaries across communities of diverse income levels (Webster et al., 2002). The trend towards gating residential areas has become a major and contemporary urban process (Caldeira, 2000; Leisch, 2002; and Landman, 2004).

In addition, this evolving urban pattern has assumed varied forms in its historical and spatial manifestations; hence the need for localized, context-specific studies. While in some cases GCs symbolize a thematic style, in others they serve pragmatic and utilitarian purposes of safety and security, or may simply be a transient fashion. Given the growing trend and accompanying academic interest, this study examined the concept of sense of security in the context of gated communities; with a view to clarifying their role in the production of place within the urban fabric of Lagos, Nigeria. Some authors hold the notion that GCs encourage spatial fragmentation and social segregation, and may thus negate place potentials (Manzi \& SmithBowers, 2005). This paper contributes to the discourse on the place potentials of GCs within the developing world, with Lagos as case-study. Despite the dearth of comprehensive base-line data on GCs in Lagos, their growing emergence is apparent, as they have gradually assumed the role of a major manifestation in the city's urban growth (Uduku, 2010).

Few pertinent questions arose: Do gated communities in Lagos represent a mere modern trend or do they derive from more serious concerns of safety or security? Are GCs driven by security and privacy needs, status and prestige motives, or the pursuit of style and fashion? What is the potential for place production in GCs? This paper is organized in six parts. Following this introductory section, the next section reviewed the literature on the driving forces, forms, and perspectives to GCs, the 
perceived primacy of security, and issues related to the production of place. While the third section provided a brief description of the research context and outlined the qualitative method utilized, the fourth presented a summary of the research findings from the analyses of the qualitative data derived from the case-studies. In the last two sections, the main results were discussed, leading to drawing a tenable conclusion.

\section{LITERATURE REVIEW}

\subsection{Overview of the Literature}

Gated communities have received much research attention from diverse fields and perspectives: architecture, environmental psychology; urban studies, urban sociology; geography; and political science. These have examined the conceptualization, emergence, significance, impacts, and planning implications of GCs for the urban milieu. The bulk of the earliest scholarly works however focused primarily on the American experience where modern versions of the phenomenon first appeared in the 1960s (McKenzie, 1994; Blakely \& Snyder, 1997; Lang \& Danielson, 1997; \& Low 2003). Research on GCs in the contexts of the developing world - Latin America/the Caribbean and Asia-Pacific regions in particular - began to assume significance only in the mid-1990s, perhaps due to the phenomenal proliferation in the number of gated developments in the mega-cities of countries such as Argentina, Brazil, China, and India (Coy \& Pohler, 2002; Webster et al., 2002; Wu \& Webber 2004; Roitman, 2005; and Thuillier, 2005).

Studies of GCs in Africa are of the most recent origin, and are relatively limited in detail, scope and comparative impact, despite evidence of the rapid growth of GCs in some major cities. They are however gradually gaining relevance in the literature (Jurgen \& Gnad, 2002; Kuppinger, 2004; Landman, 2004; Grant, 2005; Asiedu \& Arku, 2009; and Uduku, 2010). Recent studies on GCs have also focused on the causes, types, social effects, administrative implications, and urban planning and policy challenges of gated communities. The following sections reviewed the relevant literature on the driving forces, forms, and perspectives to GCs; the perceived primacy of security; and possible links with place attachment and the production of place, with a view to contextualizing these concepts and phenomena using selected case-studies in Lagos, Nigeria.

\subsection{Driving Forces, Forms and Perspectives}

Researches into the emergence of GCs range from: the works of sociologists and anthropologists who focused on the social characteristics of GCs, to urban and regional theorists who linked the upsurge of GCs to wider, globalization-related processes of economic and urban restructuring. Manzi and Smith Bowers (2005) use the club good concept to explain households' motives in becoming members of GCs. This contrasts with other explanations such as: the fortress mentality 
notions of Davis (1990); the isolationist or separatist arguments of Blakely and Snyder (1997); the unreasonable fears suggested by Low (2003); or the partitioned city arguments relating to the breakdown of civil society and emergence of a new order (Marcuse \& Kempen 2002).

Three broad, distinct, but interrelated classes of driving forces for GCs are identified in the literature, namely: security/privacy, status/prestige, and style/fashion. The issue of security relates to the perceived fear of the emergent middleclass and affluent regarding encroaching crime or 'contamination' from people of lesser socio-economic status. Status-related motives include the perceived exclusivity and other attributes of social status that gated living can ascribe. Wu (2005) examines the club realm of consumption versus the discourse of fear. The former perceives the GC as an exclusive membersonly club; the latter as a fortress to exclude intruders. With reference to the style-related motive, Glasze (2005), reflecting on the economic and political articulation of GCs, used the club goods theory to explain the potential attractiveness of GCs for developers, local governments, and residents. This theory interprets private neighbourhoods with their self-governing organisation as the creation of club economies with territorial boundaries. Allied to these broad driving factors is the ability and willingness to pay for the exclusivity and services that GCs provide. In reality however, GCs may not follow sharp class based distinctions, but be driven by a combination of these factors.

Almost synonymous with the above categorisation, Blakely (2007) identifies three forms of gated developments: lifestyle communities, prestige communities, and security zones. In lifestyle communities, gates and walls delineate areas for the pursuit of leisure and the protection of neighbourhoods, often due to the inability of local agencies to adequately protect people from various forms of urban violence. Living in such GCs often involves a certain lifestyle choice, in which the wealthy and upper-middle class combine resources to enjoy leisure and maintain local security. In the prestige/elite community, gates symbolize social status, prestige, distinction and some degree of security, especially on the social ladder. Such agglomerations feed on exclusionary aspirations and the desire to differentiate. In the security zone, the fear of crime and intruding outsiders, and the need to strengthen the feeling and function of community safety, are the prime drives for defensive fortifications. Rental and lower-income residents may constitute a substantial portion of such GCs.

The rise in GCs has been ascribed to global economic restructuring and neo-liberal policies (Low, 2003; and Grant, 2005). Roitman $(2005 ; 2010)$ suggest two classes of factors that explain the emergence and expansion of GCs: structural and subjective. The structural explanation perceives GCs as a consequence of the social, political, and economic structures of society. Structural causes relate to: (1) globalisation of the economy, leading to growing urban social inequalities, the processes of advancing social polarisation, and an increase in foreign investments; and (2) more specific concerns about the 
withdrawal of the state from the provision of basic services, including security, leading to a rise in urban violence and the privatisation of security. The subjective explanation, on the other hand, emphasizes the role of social actors: gated communities are seen as deriving from the motives and desires of these actors. Roitman identifies five subjective causes deriving from individual's desires, interests, perspectives and opportunities. These are: increased fear of crime; search for a better lifestyle; desire for a sense of community; search for social homogeneity; and aspirations for higher social status and social distinction within particular groups. Subsequent studies have supported both explanations to varying degrees, although the drivers are different for various urban contexts.

Gated communities have assumed varied forms, such as: common interest developments (CIDs) in the United States; state-led private neighbourhoods in China; low to middle income condominiums in Asian cities; security villages and neighbourhood enclosures in South Africa; closed housing estates (condominio fechado) in Brazil; private neighbourhoods (barrios privados) in Argentina; traditional gating in the Middle and Far East; and enclaves for transnational elites in many developing countries. The common characteristic is that most of these are privately managed residential enclaves. They include both new housing developments and older residential areas retrofitted with barriers and enclosures. They however differ from apartment blocks or condominium buildings with security systems or in which a doorman controls public access to private spaces such as building lobbies or hallways. GCs by contrast preclude public access to roads, sidewalks, parks, open spaces and playgrounds - spaces that would otherwise have been accessible to all (Blakely, 2007).

A seven-fold classification of gatedness by Dixon et al. (2004) includes the following features: physical barriers (walls, gates, doors, trees/hedges/greenery, speed bumps); technological barriers (surveillance cameras/videos, security alarms, access via swipe card or intercom); 'manned' surveillance (security patrols and the 'front desk' barrier); signs and markings; design features (narrowing or partly obscuring entrances, colour or texture changes, walls, doors, gates with no handles or levers); natural surveillance (being observed by residents), and implicit signals (closed unmarked doors and gates).

The increasing emergence of GCs has engendered polarised views among stakeholders. Two broad divergent perspectives subsist toward this phenomenon: GCs are either perceived as new and stimulating transformations of urban space, or as segregating, social disasters. Protagonists of GCs suggest that these residential developments may be socially sustainable in terms of: the adequate provision of services and fair distribution of opportunities within the community; the existence of a strong sense of community; and a democratic and usually participatory system of private governance. Despite the possibility of segregation, this positive notion refers to the concentration of people of like minds, which engenders group social cohesion and strengthens social networks within the urban sphere. 
Foldvary (1994) argues that GCs are more efficient in that they enhance the market's supply of collectively consumed goods in optimal quantities: the privatisation of local governance is seen as a more efficient way to achieve urban development. Social homogeneity, identity, status, security, children-oriented family living, reduced urban traffic and crime, re-establishment of trust among neighbours, and improving the quality of life are other claimed attributes of GCs (AlvarezRivadulla, 2007).

On the contrary, critics of GCs generally dismiss gating as a negative and distasteful phenomenon. They often refer to a broader segregating impact felt by those outside the gate, and the exclusion of the wider society from the opportunities available to those within. Gates, barriers, and walls are viewed as sources of segregation, discrimination, and the disintegration of society (Davis, 1998; and Low, 2003). These critics debate the notion of GCs being true communities, given their often stringent standards of conduct, extreme regulations, often mono-class and mono-cultural social structures, and the risk of increasing alienation. GCs are seen as alienating, polarising, and creating an imbalanced social system with physical, financial and cultural boundaries. They are perceived as examples of urban fortification that lead to social exclusion, segmentation, the fragmentation of urban space, and accompanying problems for urban planning and management, including the future shape of cities (Davis, 1990; 1998).

Goobler (2002) illustrates how GCs help to create social divisions and perpetuates inequality. In the UK for example, the value of GCs has been challenged by planners who view them as exclusive, unnecessary and burdensome due to movement restrictions that they promote, especially when related to other key concerns such as freedom of access to the wider city, social inclusion and territorial justice (Atkinson \& Blandy, 2005). Caldeira (2000), Blandy and Lister (2005) and Le Goix (2005) provide further evidence to support the notion that gating promotes social division and reduces social capital.

Roitman (2010) suggests positive and negative consequences of GCs, analysing these in terms of the sphere they influence: spatial, economic, political and social. Positive spatial effects include: the provision of services and amenities to areas formerly less-equipped and the creation of spaces with improved environmental quality. Negative spatial impacts are: the closure of streets, hindrance to emergency services, and fragmentation of urban space (Low, 2003). The positive economic impacts refer mainly to effects on housing, land markets and the local economy through the creation of 'economic clubs' that provide more efficient services, collectively consumed by their residents. It is argued however, that the presence of GCs can reduce property values in non-gated surrounding neighbourhoods (Le Goix, 2005). The political issues relate to the enhancement of political participation and civil engagement within the community, and reduced responsibilities for local governments. Communal provision of services and shared consumption agreements following the economic theory of clubs 
may imply political and economic benefits (Webster, 2001). In contrast, other critics project a view of the undemocratic character of GCs, in terms of the usually intrusive covenants, conditions and restrictions, which dominate life in GCs (Blakely \& Snyder, 1997). Social consequences are perhaps the most often discussed within the literature, especially the debate as to whether GCs encourage social cohesion or stimulate social segregation between the inside and the outside. Adequate attention has however not been given to the issue of place production and possible links with the security motive, which is the focus of this paper.

\subsection{Perceived Primacy of Security}

In the past two decades, increasing numbers of people globally are turning to gated communities, and there appears to be a primacy of security in the literature and discourse on GCs (Genis, 2007). Conceptually, Newman's (1973) 'defensible space' idea is assumed to be a key theoretical basis for the emergence of GCs. Newman pioneered the links between the prevention of urban decay and gating as a device that gives social control to residents over their environment. Other attempts at creating defensible space may include: suburban areas with manual or electronic bars across private access roads, and housing estates with buffer zones of lawns and cul-de-sacs, intentionally designed to exclude or deter access to non-residents.

The trend of GCs in Africa has been traced to global historic patterns of enclosure. Denyer (1978) and Oliver (1987) provide examples of historic 'fortress' settlements in diverse traditional settings. Bagaeen and Uduku (2010) identify the social-historical and cross-cultural roots of gated settlements, ranging from walled hamlets to current American models and the new transformations of the gated concept in rapidly urbanizing settings in Asia and Latin America. The authors draw connections between the historic gated homesteads and cities, and case studies of contemporary Western-style secure complexes. Citing archaeological evidence from the Nile River valleys, Mesopotamian kingdoms, and Greek and Roman territories, Blakely (2007) posits that gated cities or residential areas are as old as community building itself, and that in many parts of the world, the traditional concepts of controlled access, community ownership and private space predate the contemporary gated enclave. The Roman system of fortifying landed estates - abbeys, manor houses and castles - of the royal and wealthy later became the pattern of settlement development in England and the rest of Europe. In the case of the United States, GCs go back to the late $19^{\text {th }}$ century era of the wealthy who built private streets to insulate themselves from the masses, but they remained a relative rarity until large master-planned communities emerged in the 1960s (Blakely \& Snyder 1997).

Psychologically and physically, many gated estates are assumed to be designed to protect residents from the fear of intruders. Findings from an appreciable number of studies in diverse settings have shown that residents considered security as an essential motivation for moving to gated communities: Jurgen and Gnad (2002) in Johannesburg, South Africa; Roitman 
(2005) in Mendoza, Argentina; and Mycoo (2006) in Trinidad. Bagaeen (2010) also identifies fear and privacy as significant factors for GCs in the United States and South Africa. The latter context has in addition a long history of fortified towns such as Great Zimbabwe and a continuing fortification culture in rural homestead design (Landman, 2004). In Nigeria, the colonial antecedent to contemporary gating was the government-reserved area (GRA), a fortified enclave of residences for the rich, ruling elite. Uduku (2010) links the generic forms of gated housing at individual and neighbourhood levels, and the mushrooming of 'armoured housing' and gating in Lagos to security concerns. He opines that except for the palaces of traditional rulers, which historically had gates, the practice of creating barriers and gates, is recent to urban life in southern Nigeria, where much of urban life was centred on the interaction of residents, with the street as the site for these exchanges. The traditional city had walled and exclusive residences for chiefs and other dignitaries, as had always been the case amongst the Yoruba, who share lineage with the ancient Benin kingdom, noted for its walled city and residences.

Complementing this historical emphasis on security, Manzi and Smith-Bowers (2005) have used the theory of club goods to explain gating as a response to both real and perceived issues of crime, vandalism and antisocial behaviour. This growing need for residential fortification in a context of perceived heightened risk may be further explained based on the concept of derivative fear (Bauman, 2006). This is described as 'a sort of 'second degree' fear, a fear, so to speak, socially and culturally 'recycled" (Bauman, 2006:3). It is the 'kind of fear that guides human behaviour' whether or not a menace is imminent. Bauman's three kinds of derivative fears aroused by dangers may threaten one of more of these: the body and possessions; the social order; or individual identity. The first kind of derivative fear may be more appropriate in the context of gated communities.

\subsection{Place Attachment and Production of Place}

The perception and production of 'place' are vital aspects of the urban experience. Place has been theorised in terms of the triad of formal setting, activities and meanings (Carmona et al., 2003; Relph, 1976). 'Place' usually signifies a spatial entity that is experienced and ascribed with meaning by an individual or a group of people (Groat, 1995). Places may differ in territorial scale, ranging from rooms, home settings, and neighbourhoods, to cities and nations (Low \& Altman, 1992). Arefi (1999) stresses the notion of emotional attachment to place: the meanings particular places hold for those who use them are vital for understanding their choices and decisions. Essentially, place attachment focuses on the phenomenon of human-place bonding. It infers an intricate interaction of emotion, cognition, and behaviour in reference to place. It generally refers to "an affective bond or link between people and specific places" (Hidalgo \& Hernandez 2001:274). Such connection may depend on people's psychological state, environmental preferences, cultural values, demographic variables, experiences and 
environmental past. People can be attached to places at smaller scales such as a house or street, or at greater scales such as a city or nation. Predictors of place attachment include: length of residency; the number of relationships within a community, shared meanings, social belonging and tenure status (Hernandez et al., 2007).

Production of place implies that people live with mental geographies or symbolic understandings of places they like, dislike, fear or call home, which serve in reducing the complexity of the urban landscape (Blokland, 2008). The home or dwelling is a particularly significant type of place, whose significance is expected to increase with the complexity of urban living in contemporary societies (Easthope, 2004; Blunt \& Dowling, 2006). Though a contested concept in the literature, homes are 'places' that hold considerable social, psychological and emotive meanings for individuals and households. People find retreat in the home environment when they feel overloaded by the complexity of urban life. In many developed nations however, home is increasingly identified with suburban settings, due to urban dynamics such as industrial development, innercity crowding and traffic conditions. There appears to be a growing preference of people for the suburb and in particular gated communities - privately protected, self-controlled environments where they feel independent from the problems of the wider society.

Although much of the earlier literature tended to portray the causes and consequences of gated communities as uniform across various geographical contexts, emerging findings indicate that they are by no means a product of universal principles or conditions. The phenomenon has differing origins - social, cultural, economic, and political. Moreover, it appears from the literature that the preponderance of research has focused more on GCs in the developed nations and to some extent Latin America, than the developing world. In particular, this phenomenon has received limited attention in the Nigerian context. Despite the relatively rapid increase in the emergence of GCs in Lagos in the last few decades, and their expression as a vital aspect of the city's residential morphology, no systematic data-base is known to exist on these. There is a dearth of comprehensive and reliable data on the actual locations and number of these communities, and their population and rate of growth. Given the city's distinctive historical and colonial antecedents, the reality of GCs in the light of security issues demands closer examination; hence this study - a preliminary output from a larger on-going project aimed at developing a more robust data base of gated communities in Lagos, Nigeria.

\section{RESEARCH CONTEXT AND METHOD}

This paper is based on a study of gated communities in Lagos, Nigeria. The coastal megacity of Lagos, Nigeria 's economic hub and its largest city constitutes the major part of Lagos State, one of the thirty-six states within Nigeria's federal structure. Lagos consists of two main sections: Lagos Mainland and Lagos Island, the latter comprising the original city and 
adjoining areas of Ikoyi, Victoria Island, and Lekki peninsula. Much of the land of the Island is however occupied by offices, roads and public utilities, meaning that the residential part is densely populated. That 17 per cent of the total area consists of lagoons, creeks, and waterways, further accentuates the severe land constraints. The megacity's nodal position in the national economy derives from its being the foremost manufacturing and port city in West Africa. Being the capital of Nigeria until 1991 also contributed to rapid urban growth, in both spatial and demographic terms (Ilesanmi, 2012). Preliminary mapping exercises indicated that gated communities have become prominent features on the mainland areas of Surulere, Ebute-Meta and Ikeja, as well as along the coastal suburbs - Ikoyi, Victoria Island and Lekki. In the resolve to decongest Lagos metropolis, the many housing estates which were developed, either by government or private developers constitute the context within which the study was conducted.

Primary data was collected through a case-study research approach, using field observations and in-depth interviews with eighteen (18) residents of four (4) purposively selected gated estates out of twenty (20) estates identified from preliminary mapping exercises in Lekki area and the Lagos Mainland (Figure 1 \& 2 illustrate few of these). Two private estates in Lekki Peninsula (Victoria Garden City (VGC) and Goshen Estate) and two public estates on Lagos Mainland (Ebute-Metta \& Ijaiye) were purposively selected for their ease of access and comparativeness.

The interview schedule was designed to explore experiences of place attachment, place production, and perception or sense of security. The study used a limited sample of respondents based on the notion of strategic non-representative sampling, which aims at variation in the respondents' experiences rather than at representativeness and statistical generalization (Trost, 1986; Miles \& Huberman, 1994). Twelve (12) interviews were conducted in the latter part of 2010 with residents of the estates (three in each). Six of the interviews were with married couples, giving the total number of interviewees to be eighteen (18) nine males, nine females. The interviewees ranged in age from late thirties to early seventies; three of them were retired, one widowed and two were single. Their socio-economic status ranged from lower-medium income to high income. Ten (10) of the interviewees had children (up to teenage) who lived with them (either part-time or full-time). All interviews involved openended questions around issues such as: reasons for living in the gated estate; previous experiences, expectations and problems of gated living; length of residency; residents' preferences and descriptive evaluations of their residential settings; perception of security; experiences of attachment to place and place production; decision-making and governance issues among residents; relationships with the surrounding communities; and possibility of living again in a gated development. 

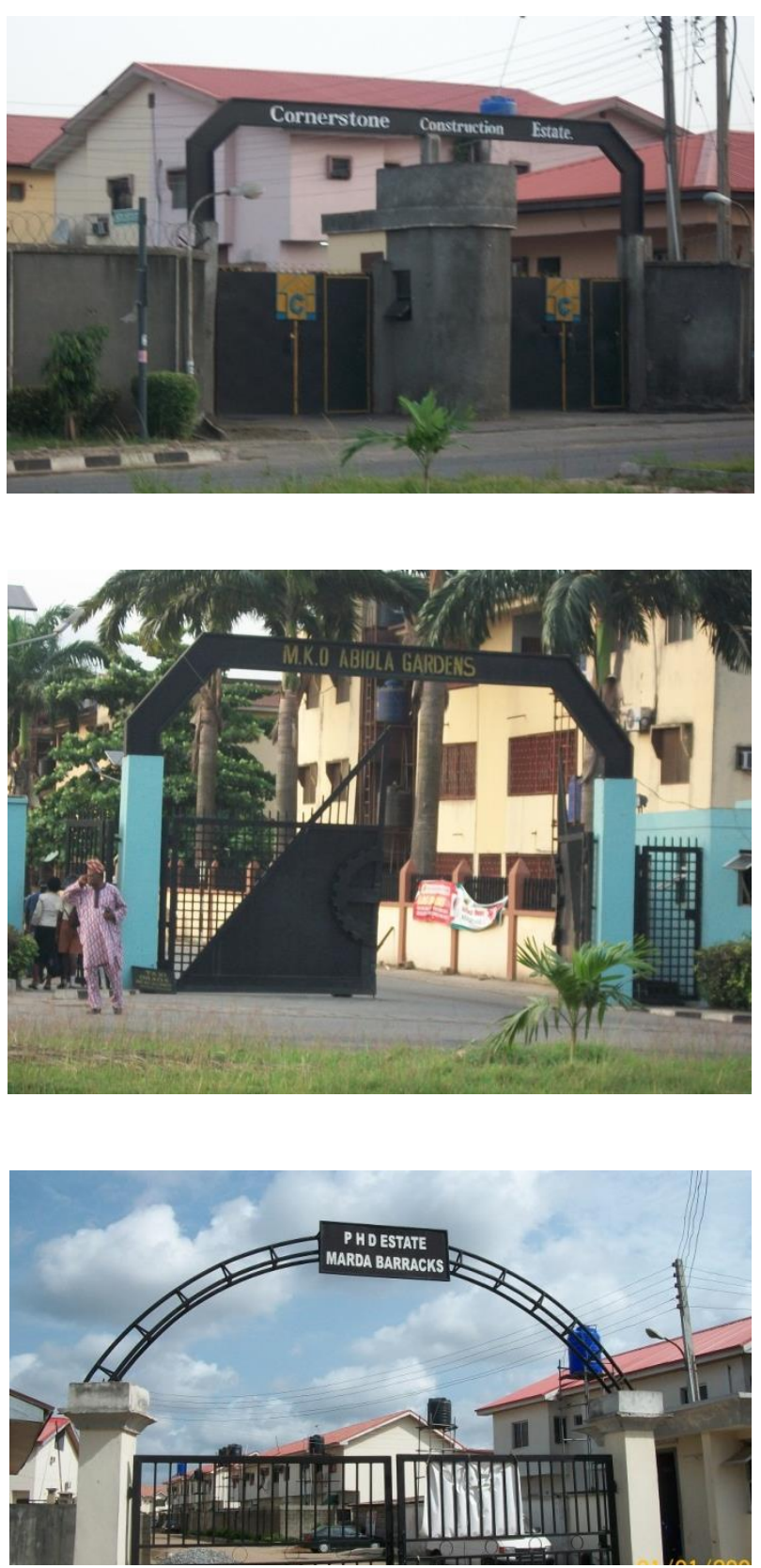

Figure 1: Gated Communities on Lagos Mainland 

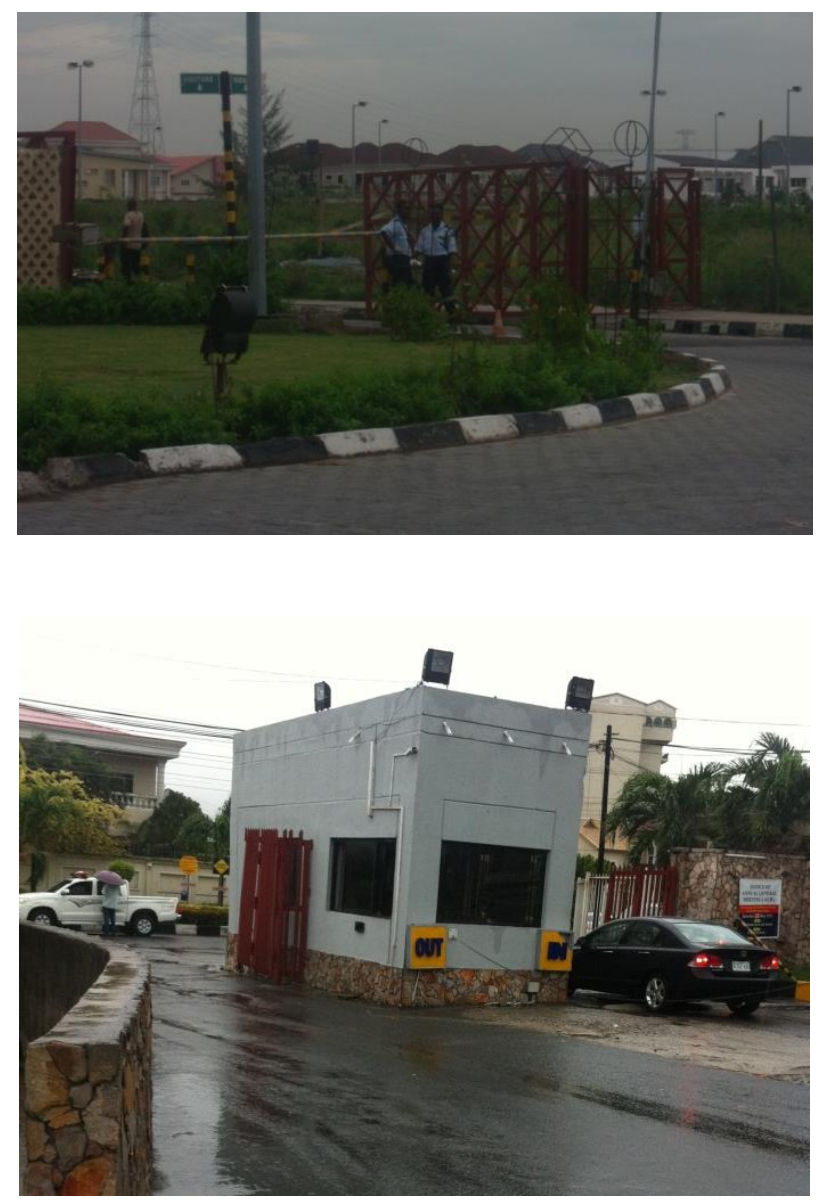

Figure 2: Gated Communities in Lekki area

The transcribed qualitative data were subjected to content analysis. Some typical questions were: To what extent do you feel emotionally attached to this residential estate? What unique feature or character of the estate do you feel attached to? How secure do you feel in this estate relative to the outside? To what extent do the security measures provided affect your feelings of attachment to this place? How has your feeling of attachment changed with time?

\section{FINDINGS}

Summarizing the results from the analysis of the qualitative data from the case-studies, the Lekki private estates reflected greater exclusivity than their Mainland public counterparts, with vehicular entry gates and pedestrian gates manned by security guards, complemented with electronic security sensors. Added to the physical fortification of the houses was the use of security dogs, electrified fences, and armed response guards. The two estates on the Mainland were provided with manually secured pedestrian gates and vehicular entries manned by security guards with tally-control for non-residents. Residents were recognised by their car-tags or other forms of identity. Secured individual gates to the residences fronting the 
road existed in all the GCs, except the Ebute-Meta estate. Using Glasze's (2005) terminology, the Lekki estates could be described as the club democracy type.

Findings from the qualitative analysis relating to perceived security, place attachment, and the production of place are summarized as follows:

\subsection{Commonality and Distinctions}

While the GCs studied exhibited some common features, there were unique distinctions between them in terms of their physical and social environments and the respondents' perceptions with respect to security and experiences of gated living. Predominantly, living in the GCs was considered primarily as a rational, utilitarian and defensible choice connected to the desire for security; but in fewer cases based on the drive for status and privacy. Different types and levels of security existed in the estates. While the Lekki estates required authorized access at the main gate and had additional home security alarms, the Ijaiye estate was more freely accessible via the pedestrian gate. Individual occupants of apartment blocks erected further barriers at their entries. However the arrangement of the blocks in the Ebute-Meta estate was such that they could not be individually gated. The common denominator in the selected estates was their quasi-autonomous organizational structure, as they operated in semi-independence of and supplementary role to local authorities. This however represents their points of departure in negotiating the production of place.

Characteristics that suggest the potential for production of place varied according to the emergence and types of the gated estates. The analysis indicated greater place prospects and potentials in the medium-income GCs in Lagos Mainland, originally built as public housing, than in the private gated estates for the more affluent in Lekki. The interviewees in the former indicated stronger emotional bonding and attachments to their communities. Notions of class exclusivity and lifestyle distinction were stronger in the Lekki estates, where the social value of living in a gated community appeared to be more important than the sense of security it accords residents. The recourse to and greater investment on more sophisticated security devices by the Lekki residents however, belies the seemingly secondary ranking of security. Some in the mainland estates emphasized on the greater flexibility they enjoyed in performing a wider range of social events - such as weddings and cultural gatherings - than would be permitted in the more exclusive high-income estates. They also shared a wider range of financial obligations relating to the security, maintenance, and servicing of their community through a thriving Residents' Association. 


\subsection{Gates and Sense of Security}

Despite residents' comments regarding the increased sense of security that gating features provided, there was consensus that they acted more as a deterrent than a barrier to access against intruders, although in all the cases, they were more than mere 'symbolic' forms. The presence of gates also provided a sense of security which engendered greater quality-oflife and perceptions of 'defensible space' than would otherwise have been the case. Two interviewees in the mainland estates illustrated this with examples of instances of burglary attempts around their neighbourhood, during which the presence of gates offered at least some psychological feeling of security. They believed that under most circumstances intruders would choose to enter a non-gated community rather than a gated one. The interviewees in the Lekki estates had no recollections of any major intrusions into their estates, but nonetheless expressed how the security features of the estates enhanced their social evaluation of their socio-spatial environments.

\subsection{Location, Social Factors and Place Attachment}

Across the four estates, most interviewees reported that their choices were based more on locational and social factors such as proximity to work places, children's schools or friends, privacy, and familiarity with neighbours, than by the mere presence of gates. What the residents of the two Lekki estates liked most were the convenience that living in such environments provided them with, in terms of paid-for services, the quiet neighbourhoods, shops and supermarkets in the vicinity, and the social atmosphere. Residents of the public estates stressed on social homogeneity shared with most of their neighbours, in terms of social class, educational status, professional networks, age-range, and ethnic lineages. These represented some of the roots of attachment.

\subsection{Past Experiences and Future Preferences}

Place attachment appeared to correlate also with the length of residency and past experiences of gating. The public housing estates were older (average of 24 years) and had more long-stay residents than the private estates (average of 10 years), and the respondents in the former expressed stronger social and spatial bonds. In addition, some of the public housing respondents had prior experiences of living in GCs. All the interviewees in the two private estates and three in the Mainland estates expressed strong likelihood of living in the same type of gated community in future if they moved from their current homes, demonstrating a strong preference and place attachment. 


\subsection{Gating, Community and Sense of Security}

Interestingly, the public estates on the Mainland showed a stronger sense of community and involvement of residents in the governance of their estates than the private ones. The Ebute-Meta interviewees in particular expressed active participation in the affairs of the Residents' Associations, which were guided by an established constitution and whose officers were democratically elected. Three respondents hinted how their active roles in the association have contributed to their selfidentity, while stressing on the far-reaching implications of these on their sense of security, confidence and ability to monitor and deter the infiltration of unwanted social miscreants, and neighbourhood cohesiveness.

\section{DISCUSSIONS}

This study revealed some distinctions between the private and public housing gated communities, and in the motives, perceptions, and experiences of the residents. On one hand were strong notions of exclusivity in the more elite estates; on the other was the primacy of security across board. Residents were primarily motivated to live in GCs for the pragmatic reason of security, and secondarily for the exclusivity and other status-related benefits that such neighbourhoods afford. However, evidence of a strong sense of community in the middle-income estate of Ijaiye showed that the gated community may not necessarily be class exclusionary and that the potential for place production is not antithetical to gated living in this context. Gating here increased the likelihood of residents getting to socialize, communicate and interact, since joint decisions were required regarding the maintenance of gates and other commonly shared services. Other aspects of gated living such as the close proximity of neighbours, working groups for communally-owned spaces and social events also resulted in neighbours getting to know one another better, with positive impacts on security-consciousness and actual security-related procedures. This explained the weaker bonding or place attachment expressed by the more economically advantaged residents of the private estates, which were primarily administered by the private property developers, rather than a Residents' Association. These also depended more on the technology-driven security measures than on socially-engineered measures.

Bauman's (2006) concept of derivative fear may explain why some residents prefer gated developments, even though gating was not necessarily their predominant initial motive. Gating could accordingly be one of the 'clever gadgets' that are employed in dealing with derivative fears, which in a sense have been de-coupled from the actual dangers that may cause them.

In spite of the assumed negative externalities of GCs, suggesting that such urban spaces lose their sense of community because of exclusion of outsiders and privatization of publicly attributed places such as streets, parks and squares, may not 
suffice in the specific contexts of the studied estates in Lagos. Gated communities have clear, geographical boundaries that can be easily managed, learned, experienced and evaluated, and thus afford the cognitive and affective processes involved in place attachment. The perceptions of people living in GCs in terms of place attachment and belongingness are germane to urban cognition, sense of identity, and perception of safety and security. The emergence of GCs may indeed be partially explained based on urban identity, which relates to differentiating residents of a certain location from other people (Lalli, 1998). The formation of identity in general is an outcome of differentiation between self and others. It could be argued that GCs may help to create distinctive environments and increase urban identity for their residents. The sense of belongingness is a major aspect of people's evaluations of their socio-spatial environments.

The enhancement of identity, sense of community, and place production could be further explained based on the governance structures of GCs: that is, the legal processes and entities associated with these developments and residents' experiences. Despite the considerable diversity in their forms and objectives, GCs irrespective of location and cultural context share similarities in terms of governance. Their quasi-autonomous organizational structure, as they operate in semiindependence of local authority governance is one major similarity between GCs in the developed and developing nations (Atkinson \& Blandy, 2005). To supplement the vacuum of local government, new models have emerged in the forms of governance by private developers, state authorities, or residents' voluntary association, each depending on the contextual characteristics (Chen \& Webster, 2005). Blandy (2007) identifies the unique difference between the fortified medieval town and the contemporary gated neighbourhood as the absence of a legal framework for contractual self-governance in the former. GCs exhibit a prevalence of private urban governance, characterized by the conspicuous absence of formal civic institutions and the empowerment of private, self-regulating commercial and social groups.

This study buttressed the assertions by Libertun de Duren (2007), that gated living often means signing up to communally agreed arrangements that allow for money to be charged for maintenance of common-buildings and shared services - physical, social, and security-related. He notes that some groups have developed innovative ways of avoiding censure from local authorities, leading to the evolution of cohesive communities of interest that provide for a serviced lifestyle. The authority for planning and management of space is thereby indirectly delegated to social groups, and is characterized by the supremacy of private governance arrangements over public regulations. Gating can help to foster social cohesion in a neighbourhood through communal efforts, by involving the wide spectrum of the community in creating management vehicles for reducing crime, protecting properties and parked vehicles, increasing safety, and enhancing the local environment by preventing unsolicited entry. If housing and planning policy makers are to take seriously a commitment to residential 
democracy and local participation, there would be no rationale for discarding GCs as examples of 'isolationism' or 'particularistic consumerist interests' (Manzi \& Smith-Bowers, 2005).

The emergence of GCs can also be viewed from the perspective of globalization and its impacts on social life, urban development and the paradoxical production of 'localization' (Washbourne et al., 1997). Owing to people's desire and demand to live in more leisurely environments and to escape from the pressures of daily life, different kinds of communities emerge where gates symbolize security and distinction. With global influences and changing urban dynamics, people's environmental preferences seem to be shifting towards private settings, leading to a process of localization. Consequently, localized neighborhoods that are independent of governmental control and management are established with new dynamics and community patterns. This is particularly with a view to reinforcing individual as well as collective and corporate sense of security based on group transactions in the negotiation and production of place. Liberalized governance systems at the local level may encourage the emergence of creative micro-governance structures within the local government framework, which could in turn favour the creation of sustainable fortified communities. There is therefore the need to encourage public openness and debate of the demerits and merits of the gated community in order for the public and the media to enter into an unbiased dialogue and debate about the issues that these communities face, the fairness of their existence and how they might better be integrated within, and contribute to, existing symbiotic sustainable public-government initiatives.

Having assumed a dominant and perhaps, permanent status in the urban morphology of Lagos megacity, it is imperative that the planning implications of gated communities be better appreciated and positively appropriated. Although the emergence of GCs in Lagos has enhanced the extension of services and amenities to areas formerly less-equipped and the creation of 'islands' with improved environmental quality, greater attention needs to be given to the 'outside-the fate' contexts between the better-serviced GCs, in order to minimize the tendency toward fragmentation of urban space. Notwithstanding the reduced responsibilities of local governments, a measure of municipal intervention is required to ensure that the positive economic effects on housing, land markets and the local economy through the creation of more efficiently-serviced 'economic clubs', do no de-value non-gated surrounding neighbourhoods. Evidence from this study of GCs in Lagos does not support a view of GCs being undemocratic. Although this study has not fully answered the question of whether GCs encourage social cohesion or stimulate social segregation between the inside and the outside, the reality of GCs in Lagos based essentially on the security need, demands the adoption of ingenious planning strategies to amplify the potential benefits against the possible tendency towards segregation. Participatory approaches to the planning process, and active effort at community education via grassroots groups and local government initiatives, may prove valuable in this wise, to obtaining meaningful residents' contributions. 


\section{CONCLUSION}

This paper explored the potential for place attachment and the production of place in selected gated communities in Lagos, Nigeria. It examined how the need for security could be viewed as a positive factor in the negotiation of place through the communal cooperation of residents. The findings reveal that characteristics that suggest the potential for production of place vary according to the evolution and types of the gated developments. The medium-income GCs originally built as public housing evidenced greater place potentials than the more elitist private gated estates. Although preliminary in nature and limited in scope, this study indicated that few unique attributes of GCs, such as the perception and provision of security and social interactions engendered by their private governance structure may contribute to place attachment and production of place. It can be concluded that the security-driven motive of gated communities could contribute positively as a dominant factor in the negotiation of place; thus reinforcing the link between perception of security and production of place in the gated communities.

Further empirical research would be useful to cover a broader range of GCs in Lagos megacity, as well as ascertain the perception, not only of residents within the GCs, but also of the estate developers, local authorities, and those outside the gates. The study however points to beneficial prospects for gated living as a sustainable urban form in Lagos. As long as the security challenges in Lagos persist, gated communities would potentially remain a desirable model of sustainable microcommunity through which service and infrastructure delivery, energy sourcing and other forms of community initiatives, especially those related to security, can thrive at the neighbourhood level through the pooling of social capital. It signifies the local manifestation of a global phenomenon within the gamut of the production of place.

\section{REFERENCES}

Alvarez-Rivadulla, M. J. (2007). Golden Ghettos: Gated communities and class residential segregation in Montevideo, Urugua. Environment and Planning A, 39, 47 - 63.

Arefi, M. (1999). Non-place and placelessness as narratives of loss: Rethinking the notion of place. Journal of Urban Design, 4, 175-194.

Asiedu, A. B., \& Arku, G. (2009). The rise of gated housing estates in Ghana: Empirical insights from three communities in metropolitan Accra. Journal of Housing and the Built Environment, 24, 227-247.

Atkinson, R., \& Blandy, S. (2005). Introduction: International perspectives on the new enclavism and the rise of gated communities. Housing Studies, 20(2), 177-186.

Bagaeen, S. (2010). Gated Histories: An introduction to themes and concepts. In S. Bagaeen \& Uduku, O. (Eds.), Gated Communities, pp.1-8. London: Earthscan.

Bagaeen, S., \& Uduku, O., (Eds.). (2010). Gated Communities. London: Earthscan.

Bauman, Z. (2006). Liquid Fear. Cambridge: Polity Press. 
Blakely, E. J. (2007). Guest editor's introduction: Gated communities for a frayed and afraid world. Housing Policy Debate, $18(3), 475-480$.

Blakely, E. J., \& Snyder, M. G. (1997). Fortress America: Gated communities in the United States. Washington DC; Cambridge, MA: Brookings Institution Press; Lincoln Institute of Land Policy.

Blandy, S. (2007). Gated communities in England as a response to crime and disorder: Context, effectiveness and implications. People, Place and Policy Online, 1(2), 47-54.

Blandy, S., \& Lister, D. (2005). Gated communities: (Ne)gating community development? Housing Studies. 20(2), $287-301$.

Blokland, T. (2008). You got to remember you live in public housing: Place-making in an American housing project. Housing, Theory and Society, 25(1), 31-46.

Blunt, A., \& Dowling, R. (2006). Home. London: Routledge.

Caldeira, T.P.R. (2000) City of walls: Crime, segregation, and citizenship in Sao Paolo. University of California Press: Berkeley, CA.

Carmona, M., Heath, T., Oc, T., \& Tiesdell, S. (2003). Public places, urban spaces: The dimensions of urban design. Oxford: Architectural Press.

Chen, S. C. Y., \& Webster, C. J. (2005). Homeowners associations, collective action and the costs of private governance. Housing Studies, 20(2), 205-220.

Coy, M., \& Pohler, M. (2002). Gated communities in Latin America megacities: Case studies in Brazil and Argentina. Environment and Planning B: Planning and Design, 29, 355-370.

Davis, M. (1990). City of Quartz: Excavating the future in Los Angeles. London: Verso.

Davis, M. (1998). Ecology of fear. New York: Metropolitan Books.

Denyer, S. (1978). African traditional architecture. Africana Publishing Company: New York.

Dixon, J., Dupuis, A., \& Lysnar, P. (2004). Gated communities: Urban innovation or fortification. Planning Quarterly, 152, 912.

Easthope, H. (2004). A place called home. Housing, Theory and Society. 20(3), 128-138.

Foldvary, F. (1994) Public goods and private communities: The market provision of social services. Edward Elgar Publishers: Aldershot, Hants, England, Brookfield, Vt.

Genis, S. (2007). Producing elite localities: The rise of gated communities in Istanbul. Urban Studies, 44(4), $771-798$.

Glasze, G. (2005). Some reflections on the economic and political organisation of private neighbourhoods. Housing Studies, $20(2), 221-233$.

Goobler, A. (2002) Outside the walls: Urban gated communities and their regulation within the British planning system. European Planning Studies, 10(3), 321-335.

Grant, R. (2005). The emergence of gated communities in a West African context: Evidence from Greater Accra, Ghana. Urban Geography, 26(8), 661-683.

Groat, L., ed. (1995). Giving places meaning. London: Academic Press.

Hernandez, B., Hidalgo, M. C., Salazar-Laplace, M.E., \& Hess, S., (2007). Place attachment and place identity in natives and non-natives. Journal of Environmental Psychology, 27, 310-319. 
Hidalgo, M. C., \& Hernandez, B. (2001). Place attachment: Conceptual and empirical questions. Journal of Environmental Psychology, 21, 273-281.

Ilesanmi, A. O. (2012). Lagos, Nigeria. In: Birkshire Encyclopedia of Sustainability, Volume 9: Afro-Eurasia: Assessing Sustainability (pp.174-177). Great Barrington, MA: Birkshire Publishing Group, LCC.

Jurgen, U., \& Gnad, M. (2002). Gated communities in South Africa - experiences from Johannesburg. Environment and Planning B: Planning and Design, 29, 337-353.

Kuppinger, P. (2004). Exclusive greenery: New gated communities in Cairo. City and Society, 16(2), 35-62.

Lang, R., \& Danielsen, K. (1997). Gated communities in America: Walling out the world? Housing Policy Debate, 8(4), 725727.

Lalli, M. (1998). Urban Identity. Trans. H. Dittmar. In D. Canter (Ed.), Environmental Social Psychology. London: Academic Publishers, 303-311.

Landman, K. (2004). Gated communities in South Africa. The challenge for spatial planning and land use management. Town Planning Review, 75(2), 151-172.

Le Goix, R. (2005). Gated communities: Sprawl and social segregation in Southern California. Housing Studies, 20(2), 323343.

Leisch, H. (2002). Gated Communities in Indonesia. Cities, 19, 341-350.

Libertun, de Duren, N. R. (2007). Gated communities as a municipal development strategy. Housing Policy Debate, 18, 607626.

Low, S. (2003) Behind the Gates: Life Security and the Pursuit of Happiness in Fortress America. London: Routledge.

Low, S. M., \& Altman, I. (1992). Place attachment: A conceptual inquiry. In S. M. Low \& I. Altman (Eds.), Place Attachment, pp. 1-12. New York: Plenum.

Manzi, T., \& Smith-Bowers, B. (2005). Gated communities as club goods: Segregation or Social Cohesion? Housing Studies, $20(2), 345-359$.

Marcuse, P., \& Kempen, R., eds. (2002). Of states and cities: The partitioning of urban space. Oxford: Oxford University Press.

McKenzie, E. (1994). Privatopia: Homeowner associations and the rise of residential private government. New Haven and London: Yale University Press.

Miles, M. B., \& Huberman, A. M. (1994). Qualitative data analysis: An expanded sourcebook (2 ${ }^{\text {nd }}$ ed.), Thousand Oaks, CA: Sage.

Mostowska, M. (2007). Book Review. Journal of Housing and Built Environment, 22, 231-234.

Mycoo, M. (2006). The retreat of the upper class and middle classes to the gated communities in the poststructural adjustment era: The case of Trinidad. Environment and Planning A, 38, 131-148.

Newman, O. (1973). Defensible space. London: Architectural Press.

Oliver, P. (1987). Dwellings: The house across the world. Phaidon: Oxford.

Relph, E. (1976). Place and placelessness. London: Pion.

Roitman, S. (2005). Who segregates whom? The analysis of a gated community in Mendoza, Argentina. Housing Studies, 20(2), 303-321. 
Roitman, S. (2010). Gated communities: definitions, causes and consequences. Urban Design and Planning, 163(DP1), 31-38.

Thuillier, G. (2005). Gated communities in the metropolitan area of Buenos Aires, Argentina: A challenge for town planning. Housing Studies, 20(2), 255-271.

Trost, J. (1986). Statistically nonrepresentative stratified sampling: a sampling technique for qualitative studies. Qualitative Sociology, 9, 54-57.

Uduku, O. (2010). Urban Gating as the Default Condition. In: S. Bagaeen and O. Uduku, eds., Gated Communities, pp. 39-47. London: Earthscan,

Washbourne, N., Albrow, M., Eade, J. \& Dürrschmidt, J. (1997). The Impact of Globalization on Sociological Concepts. In J. Eade (Ed.) Living the Global: Globalization as Local Process, pp. 20-35. London: Routledge.

Webster, C. (2001). Gated cities of tomorrow: a pragmatic path to urban reform. Town Planning Review, 72(2), 149-169.

Webster, C., Glasze, G. \& Frantz, K. (2002). The global spread of gated communities. Environment and Planning B: Planning and Design, 29, 315-320.

Wu, F. (2005). Rediscovering the 'gate' under market transition: From work-unit compounds to commodity housing enclaves. Housing Studies, 20(2), 235-254.

Wu, F., \& Webber, K. (2004). The rise of "foreign gated communities"' in Beijing: Between economic globalization and local institutions. Cities, 21(3), 203-213. 